\title{
Antimicrobial, Antifungal \& Cytotoxic Activities Screening of Stem Bark Fractions from Terminalia chebula
}

\author{
Md. Lutful Kabir ${ }^{1}$, Mohammad Tuhin Ali ${ }^{2}$, Md. Enamul Haque ${ }^{2, *}$ \\ ${ }^{1}$ Department of Biochemistry and Molecular Biology, \\ Bangabandhu Sheikh Mujibur Rahman Science \& Technology University, Bangladesh \\ ${ }^{2}$ Department of Biochemistry and Molecular Biology, University of Dhaka, Bangladesh \\ *Corresponding Author: enamulmd@du.ac.bd
}

Copyright $\bigcirc 2017$ by authors, all rights reserved. Authors agree that this article remains permanently open access under the terms of the Creative Commons Attribution License 4.0 International License

\begin{abstract}
The fractionated crude extracts and two isolated pure compounds TC-1(Phytol) and TC-2(Stigmasterol) from stem bark of Terminalia chebula were screened for their antibacterial and antifungal activities and cytotoxicity against brine shrimp nauplii. Petroleum ether, ethyl acetate (EtOAc) and methanol (MeOH) extracts and the compounds isolated from EtOAC fractions were studied for their antimicrobial activities. Cytotoxic activities were conducted only with crude extract. Both EtOAc and petroleum ether extract showed promising and moderate antimicrobial activities against most of the gram positive and gram negative bacteria whereas the $\mathrm{MeOH}$ extract did not show any antimicrobial activities. The isolated pure compounds TC- 1 \& TC- 2 exhibited activities against most of the bacterial strains. The cytotoxicity towards brine shrimp nauplii of the crude extract was studied. The $\mathrm{LC}_{50}$ values of plant crude extract is found to be $5.623413 \mu \mathrm{g} / \mathrm{mL}$.
\end{abstract}

Keywords Antimicrobial, Cytotoxic. Terminalia chebula

\section{Introduction}

Terminalia chebula is an important medicinal plant in Indian traditional medicine and it is most frequently used herb in Ayurveda. The genus Terminalia consists of 250 species and widely distributed in tropical areas of the world [1]. Terminalia chebula is a medium- to large-sized tree distributed throughout tropical and subtropical Asia, including China and Tibet. This tree is found in the forests of northern India, Uttar Pradesh and Bengal, and is common in Tamil Nadu, Karnataka and southern Maharastra. Terminalia chebula is commonly known as black myroblans in English and harad in Hindi [1]. Antibacterial activity of Terminalia chebula extracts against several bacterial strains have been reported [2]. Extracts from different parts of diverse species of plants like root, flower, leaves, seeds, etc. exhibit antibacterial properties were applied on cotton material for wound, healthcare care application [3]. It is a well-known fact that the demand for the herbal drug treatment of various ailments is increasing and plant drugs from the ayurvedic system are being explored more, not only in India but also globally. As a result, many research studies are being undertaken and there is a need for an update and to put them together. In this article an attempt has taken to recapitulate available pharmacological studies for Terminalia chebula. Fruits are stomachic, tonic, carminative, expectorant and antidysenteric; useful in asthma, sore throat, stomatitis, heart diseases, bleeding piles, leucoderma, constipation, painful menstruation and indigestion; applied externally to chronic ulcers and wounds. It is also used in fever, urinary diseases, rheumatism, flatulence, hiccup, colic, and enlarged spleen and liver. The unripe fruit is astringent and aperient, useful in dysentery and diarrhoea. The ripe fruit is purgative, tonic and carminative; good in ophthalmia, diseases of the spleen and piles. Powdered fruit is useful in carious teeth, bleeding and ulcerated gums. Bark is diuretic and cardiotonic.

Ethanolic extract of the leaf possesses wide range of antibacterial and antifungal properties [4]. Some antibacterial compounds have been isolated from the fruits. Chebulin present in the fruit exerts antispasmodic activity on smooth muscles [5].So far no detail phytochemical and biological studies have been carried out on stem bark of this plant. In the present study, antimicrobial activities of the crude extracts and isolated compounds from EtOAc extract and cytotoxic activities of the EtOAc and selected fractions of the stem bark of Terminalia chebula have been discussed.

\section{Materials and Methods}

The stem bark of Terminalia chebula was collected from the forest of Gazipur district of Bangladesh. The sun-dried stem bark was ground mechanically and extracted in a 
soxhlet apparatus successively with petroleum ether, ethyl acetate and methanol. The extracts were then concentrated in vacuo using a Buchi rotavapor. The EtOAc extract was then fractionated by vacuum liquid chromatography (VLC) over silica gel. Pure compounds were then isolated and purified from different fractions using different types of chromatographic techniques. The in vitro antibacterial and antifungal activities of the crude extracts as well as the isolated pure compounds were determined by disc diffusion technique [6].Sixteen bacterial strains, which included six gram positive and nine gram negative organisms and eight fungi, were collected from the Department of Microbiology and Institute of Nutrition and Food Sciences, University of Dhaka. Nutrient agar media was used for the culture of bacteria and potato dextrose agar media was used for the culture of fungi. In brief, a measured amount of the test samples was dissolved in definite volumes $\mathrm{CHCl}_{3}$ to give solutions of known concentration $(\mu \mathrm{g} / \mathrm{ml})$. The sterile Matricel (BBL, cocksville USA) filter paper discs were impregnated with known amounts of the test substances and dried. Standard antibiotic disc $(10 \mu \mathrm{g} / \mathrm{ml})$ and disc on which $\mathrm{CHCl}_{3}$ was adsorbed and dried (blank disc) were used as positive and negative controls, respectively. The disc was then placed in petridises $(120 \mathrm{~mm}$ in diameter) containing Mueller- Hinton agar media seeded with the test organisms using sterile cotton swabs. The plates were then incubated at $37^{\circ} \mathrm{C}$ for 24 hours. The antimicrobial activities were measured from zone of inhibition expressed in $\mathrm{mm}$. All experiments were carried out in triplicate and the mean of the readings were recorded [7]. The cytotoxic activities were performed by Brine shrimp lethality test [8].

\section{Results and Discussion}

The metabolic extract of plant stem bark and different partitionates were subjected to antimicrobial screening. The results are given in the below table 1 .

Table 1. Antibacterial activities of different extracts and compounds of Terminalia chebula

Zone of inhibition $(\mathrm{mm} \pm \mathrm{SD})$

\begin{tabular}{|c|c|c|c|c|c|}
\hline $\begin{array}{l}\text { Bacteria } \\
(3 \mathrm{mg} / \text { disc) }\end{array}$ & $\begin{array}{l}\text { Pet. Ether extracts } \\
\qquad(3 \mathrm{mg} / \text { disc })\end{array}$ & $\begin{array}{l}\text { EtoAc extract } \\
(100 \mu \mathrm{g} / \text { disc })\end{array}$ & $\begin{array}{c}\text { TC- } 1 \\
(100 \mu \mathrm{g} / \mathrm{disc})\end{array}$ & $\begin{array}{c}\mathrm{TC}-2 \\
(100 \mu \mathrm{g} / \mathrm{disc})\end{array}$ & Ciprofloxacin \\
\hline \multicolumn{6}{|l|}{ Gram positive } \\
\hline Bacillus cereus & $9 \pm 0.3$ & $8 \pm 0.5$ & $9 \pm 0.3$ & $7 \pm 0.2$ & $18 \pm 0.3$ \\
\hline Bacillus polymyx & - & $7 \pm 0.2$ & - & $8 \pm 0.4$ & $15 \pm 0.2$ \\
\hline Bacillus subtilis & $12 \pm 0.4$ & $9 \pm 0.6$ & $13 \pm 0.8$ & $10 \pm 0.6$ & $18 \pm 0.2$ \\
\hline Bacillus megaterium & $m \quad 8 \pm 0.2$ & - & $8 \pm 0.3$ & - & $16 \pm 0.3$ \\
\hline Sarcina lutea & - & - & - & - & $20 \pm 0.4$ \\
\hline Staphylococcus aure & reus $9 \pm 0.3$ & $10 \pm 0.7$ & $9 \pm 0.4$ & $11 \pm 0.7$ & $19 \pm 0.2$ \\
\hline \multicolumn{6}{|l|}{ Gram negative } \\
\hline Vibrio minicus & $8 \pm 0.3$ & $7 \pm 0.2$ & $7 \pm 0.4$ & $8 \pm 0.3$ & $19 \pm 0.4$ \\
\hline Vibrio cholera & $11 \pm 0.7$ & $12 \pm 0.5$ & $11 \pm 0.6$ & $9 \pm 0.5$ & $21 \pm 0.3$ \\
\hline Salmonella typhi & $7 \pm 0.5$ & $8 \pm 0.6$ & $10 \pm 0.5$ & $8 \pm 0.4$ & $20 \pm 0.2$ \\
\hline Shigella boydii & - & $9 \pm 0.4$ & - & $11 \pm 0.7$ & $22 \pm 0.3$ \\
\hline Shigella Flexnari & $8 \pm 0.2$ & $7 \pm 0.3$ & $7 \pm 0.2$ & - & $19 \pm 0.4$ \\
\hline \multicolumn{6}{|l|}{ Type-1 } \\
\hline Shigella dyst & $9 \pm 0.7$ & - & $8 \pm 0.3$ & $8 \pm 0.5$ & $18 \pm 0.2$ \\
\hline Pseudomonassp. & $9 \pm 0.4$ & $8 \pm 0.6$ & $9 \pm 0.7$ & $8 \pm 0.2$ & $17 \pm 0.3$ \\
\hline Klebsiella sp. & - & - & $8 \pm 0.5$ & $7 \pm 0.3$ & $15 \pm 0.3$ \\
\hline Escherchia coli. & $12 \pm 0.8$ & $10 \pm 0.3$ & $11 \pm 0.8$ & $9 \pm 0.7$ & $18 \pm 0.2$ \\
\hline
\end{tabular}

Here '-' indicates no zone of inhibition 
No antimicrobial activity was found for methanolic extract. on the other hand, petroleum ether soluble fraction and ethyl acetate soluble fraction showed mild to moderate antimicrobial activity (ranging from 7 to $12 \mathrm{~mm}$ ) compared with standard antibiotic disk ciprofloxacin which possessed zone of inhibition (ranging from 15 to $22 \mathrm{~mm}$ ). In case of gram positive bacteria petroleum ether soluble fraction possessed highest zone of inhibition on Bacillus subtilis $(12 \mathrm{~mm})$ and no zone of inhibition on Bacillus polymyxa and Sarcina lutea. In case of gram positive bacteria ethyl acetate soluble fraction possessed highest zone of inhibition on Staphylococcus aureus $(10 \mathrm{~mm})$ and no zone of inhibition on Bacillus megaterium and Sarcina lutea. In case of gram negative bacteria petroleum ether soluble fraction possessed highest zone of inhibition on Escherchia coli $(10 \mathrm{~mm})$ and no zone of inhibition on Shigella boydii and Klebsiella sp. In case of gram negative bacteria ethyl acetate soluble fraction possessed highest zone of inhibition on Vibrio cholera $(12 \mathrm{~mm})$ and no zone of inhibition on Shigella dyst and Klebsiella $s p$.

After isolation of the two compounds almost all the organism are moderately sensitive to the two compounds. In case of gram positive bacteria TC-1 possessed highest zone of inhibition on Bacillus subtilis (13mm) and no zone of inhibitions was found on Bacillus polymyxa and Sarcina lutea. In case of gram negative bacteria TC-1 possessed highest zone of inhibition on Escherchia coli $(11 \mathrm{~mm})$ and no zone of inhibitions was found on Shigella boydii. In case of gram positive bacteria TC-2 possessed highest zone of inhibition on Staphylococcus aureus $(11 \mathrm{~mm})$ and no zone of inhibitions was found on Bacillus megaterium and Sarcina lutea. In case of gram negative bacteria TC-2 possessed highest zone of inhibition on Shigella boydii $(11 \mathrm{~mm})$ and no zone of inhibitions was found on Shigella flexneri type-1.

For Blank where only chloroform soluble disc were used no zone of inhibition were found.

\subsection{Antifungal Activity of the Crude Extract and Fractions}

The crude extracts and fractions 1,2 were investigated against fungi. This crude extract was used in concentration $3 \mu \mathrm{g} /$ disc and the activity observed is list bellow in table-2.

The crude extract and compounds TC- 1 \& TC- 2 has shown promising zone of inhibition against the fungi except Aspergillus fumigate Rhizopus oryzae and Candida krusii. The grisofulvin showed antifungal activity (ranging from 8 to $12 \mathrm{~mm}$ ).In case of TC-1 highest zone of inhibition found on Candida arrizae $(9 \mathrm{~mm})$ and lowest zone of inhibition found on Saccharomyces cerevisiae ( $7 \mathrm{~mm})$. In case of TC-2 highest zone of inhibition found on Aspergillus niger (10mm) and lowest zone of inhibition found on Candela albicans (7mm).

Table 2. Antifungal activities of crude extract and compounds of Terminalia chebula

\begin{tabular}{|c|c|c|c|c|}
\hline \multirow{2}{*}{ Names } & \multicolumn{4}{|c|}{} \\
\cline { 2 - 5 } & Crude extract $(3 \mu \mathrm{g} / \mathrm{disc})$ & TC-1 $(100 \mu \mathrm{g} / \mathrm{disc})$ & TC-2 $(100 \mu \mathrm{g} / \mathrm{disc})$ & Grisofulvin $(100 \mu \mathrm{g} / \mathrm{disc})$ \\
\hline Candida arrizae & $10 \pm 0.3$ & $9 \pm 0.5$ & $8 \pm 0.3$ & $12 \pm 0.2$ \\
\hline Aspergillus fumigate & - & - & - & - \\
\hline Aspergillus niger & $9 \pm 0.6$ & $8 \pm 0.3$ & $10 \pm 0.5$ & $8 \pm 0.3$ \\
\hline Rhizopus oryzae & - & - & - & $11 \pm 0.4$ \\
\hline Candida albicans & $8 \pm 0.5$ & - & - & - \\
\hline $\begin{array}{c}\text { Saccharomyces } \\
\text { cerevisiae }\end{array}$ & $7 \pm 0.2$ & $7 \pm 0.4$ & - & $9 \pm 0.2$ \\
\hline Candida krusii & - & - & - & \\
\hline
\end{tabular}

Table 3. Determination of $\mathrm{LC}_{50}$ of brine shrimp lethality bioassay for plant extract of Terminalia chebula

\begin{tabular}{|c|c|c|c|c|c|c|c|}
\hline $\begin{array}{c}\text { Methanol } \\
\text { extract }\end{array}$ & & & & $\begin{array}{l}\text { Vincristine } \\
\text { sulfate }\end{array}$ & & & \\
\hline $\begin{array}{l}\text { Conc. }(\mathrm{c}) \\
(\mu \mathrm{g} / \mathrm{mL})\end{array}$ & $\log c$ & $\% \mathrm{LC}_{50}$ & $\begin{array}{l}\text { Mortality } \\
(\mu \mathrm{g} / \mathrm{mL})\end{array}$ & $\begin{array}{l}\text { Conc.(c) } \\
(\mu \mathrm{g} / \mathrm{mL})\end{array}$ & $\log c$ & $\% \mathrm{LC}_{50}$ & $\begin{array}{l}\text { Mortality } \\
(\mu \mathrm{g} / \mathrm{mL})\end{array}$ \\
\hline 400 & 2.602 & 100 & & 20.0 & 1.300 & 100 & \\
\hline 200 & 2.301 & 100 & & 10.0 & 1.000 & 100 & \\
\hline 100 & 2.000 & 100 & & 5.0 & 0.698 & 90 & \\
\hline 50 & 1.699 & 90 & & 2.5 & 0.397 & 80 & \\
\hline 25 & 1.398 & 80 & 5.623413 & 1.25 & 0.096 & 70 & 9.315 \\
\hline 12.5 & 1.097 & 60 & & 0.625 & -0.204 & 60 & \\
\hline 6.25 & 0.796 & 50 & & 0.313 & -0.488 & 40 & \\
\hline 3.125 & 0.495 & 40 & & 0.156 & -0.806 & 40 & \\
\hline 1.536 & 0.194 & 30 & & 0.078 & -1.107 & 30 & \\
\hline 0.0 & 0.0 & 0.0 & & 0.0 & 0.0 & 0.0 & \\
\hline
\end{tabular}




\subsection{Cytotoxic Activities of Terminalia chebula}

Plotting of $\log$ of concentration (on X-axis) Vs percent of mortality (on Y-axis) is given below:

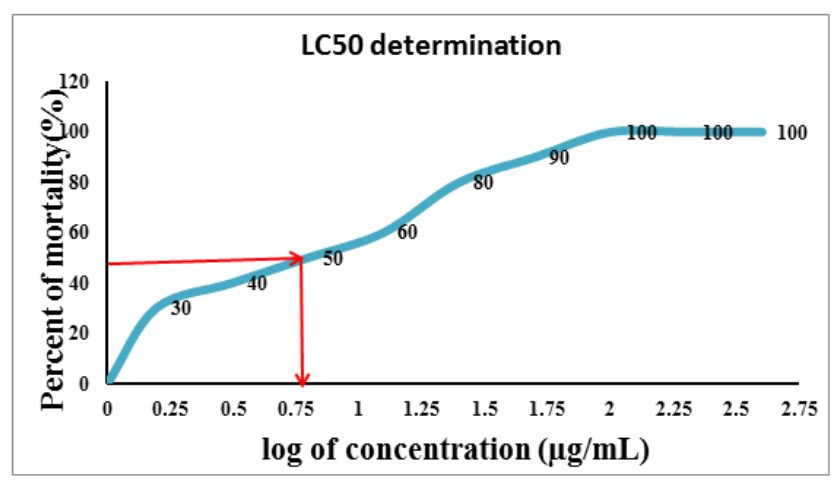

Calculation:

$\mathrm{LC}_{50}=$ anti-log at $50 \%$ mortality

From figure-5.2,

$\mathrm{LC}_{50}=\operatorname{anti}-\log \mathrm{C}$

$=\operatorname{anti}-\log (0.75)$

$=5.623413$

It appears from the result that all the test samples were lethal to brine shrimp nauplii. In the present bioactivity study, all the crude extracts, pre-ether, carbon tetrachloride, dichloromethane, ethyl acetate and aqueous soluble fractions of methanolic extract showed positive results indicating that the test samples were biologically active. Each of the test samples showed different mortality rate at different concentrations. Plotting of Log of concentration Vs Percent of mortality for all test samples showed an approximate linear correlation. From the graph, the median lethal concentration $\left(\mathrm{LC}_{50}\right.$, the concentration at which $50 \%$ mortality of brine shrimp nauplii occurred) was determined for the samples. The lethal concentration $\mathrm{LC}_{50}$ of the test samples after 24 hours was obtained by a plot of percentage of the Shrimps died against the logarithm of the sample concentration (toxicant concentration) and the best fit-line was obtained from the curve data by means of regression analysis. Vincristine sulfate (VS) was used as positive control and the lethal concentrations $\left(\mathrm{LC}_{50}\right)$ were found $9.315 \mu \mathrm{g} / \mathrm{mL}$ for vincristine sulfate. Comparing with the positive control gave significant mortality and the $\mathrm{LC}_{50}$ values of the different extractives were compared to this positive control. Among the different extractives of Terminalia chebula chloroform soluble fraction showed significant lethality having the $\mathrm{LC}_{50}$ value $5.623413 \mu \mathrm{g} / \mathrm{mL}$.
The positive control group show nonlinear mortality rates at lower concentrations and linear rates at higher concentrations. There was no mortality in the negative control groups indicating the test as a valid one and the results obtained are only due to the activity of the test agents.

\section{Conclusions}

From this investigation it has been found that this plant showed a number of promising biological activities including antibacterial, antifungal and cytotoxic. Therefore it would be a good source of natural medicine. To achieve this further investigation on this plant is required

\section{REFERENCES}

[1] Ammar S, Michael H, Pirkko H, Kalevi P (2002). Inhibition of Cancer Cell Growth by Crude Extract and the Phenolic of Terminalia chebula Fruit. J. Ethnopharmacol. 81:327-336.

[2] Bag, A. Bhattacharyya, SK. Bharati, P. Pal, NK, and Chattopadhyay, R. Evaluation of antibacterial properties of Chebulic myrobalan (fruit of Terminalia chebula Retz.) extracts against methicillin resistant Staphylococcus aureus and trimethoprim-sulphamethoxazole resistant uropathogenic Escherichia coli, Afr. J. Plant Sci. 2009, 3(2), 025-029

[3] Jothi, D. Experimental study on antimicrobial activity of cotton fabric treated with aloe gel extract from Aloe vera plant for controlling the Staphylococcus aureus (bacterium).African Journal of Microbiology Research. 2009, 3(5), 228-232.

[4] Begum, J., Yusuf, M., Chowdhury, J.U., Khan, S. and Nural, A.M. (2007) Antifungal Activity of Forty Higher Plants against Phytopathogenic Fungi. Bangladesh Journal of Microbiology, 24, 76-78.

[5] Ghani, A. 2003. Medicinal Plants of Bangladesh with chemical constituents and uses .2nd edition.

[6] Baucr. A.W., Kirby, W.M.M., Shenis. J.C. and Turck, M. 1966. Antibiotic susceptibility testing by standardized single disc method Am J. Clin.Parhol. 44.493-496.

[7] Jones. N.R. Bany, L.A. Gavan. L.T. and Washington, J.A. 1985. Manual of clinical Microbiology. 4th End. p. 472. American Soc. Microbial. 1913 st. N.W. Washington. DC.

[8] Mclaughlin. J.L. and Anderson, J.E. 1990. Bench top bioassays for the discovery of bioactive compounds in higher plants. Brenesa. 29.443. 